Z. Klin. Chem. Klin. Biochem.

11. Jg. 1973 , S. $159-166$

\title{
Effects of Chronic Alcohol Abuse on the Fatty Acid Composition of Major Lipids in the Human Brain
}

\author{
Hepatocerebral Degeneration, $I I$.
}

\author{
By P. Lesch, Ellen Schmidt and F. W. Schmidt
}

Gastroenterol. Abteilung, Dept. Innere Medizin, Medizinische Hocbschule Hannover

(Eingegangen am 3. August/20. November 1972)

The fatty acids of cerebrosides, sphingomyelins, phosphatidyl cholines and phosphatidyl ethanolamines from 4 different regions of 6 human brains with alcoholic "hepatocerebral degeneration" were examined and compared with those from 6 normal brains. - A significant or slight decrease of long chain fatty acids in the cerebrosides, sphingomyelins and phosphatidyl cthanolamins was found in the grey matter of the cortex. These changes were interpreted as indicating a typical degenerative process. In the areas of white matter a lengthening of the $C$-chain of fatty acids in cerebrosides and sphingomyelins was noted as well as an increase of the polyenoic acids in the phosphatidyl ethanolamines. These changes are considered to indicate an atypical type of degeneration. Similar changes in other diseases of the brain have not yet been described. - The chemical changes did not correlate with the histology, the changes of which were very slight, but they did parallel the clinical picture, as all abnormal brains were derived from patients with hepatic failure and advanced neurological and mental symptoms.

Untersucht wurden die Fettsäuren der Cerebroside, Sphingomyeline, Phosphatidylcholine und Phosphatidyläthanolamine aus 4 verschiedenen Regionen 6 menschlicher Gehirne mit alkohol-toxischer "hepatocerebraler Degeneration" (hepatoportale Encephalopathie) und 6 Normalgehirnen. - In der grauen Substanz des Cortex findet man eine signifikante oder geringe Abnahme der langkettigen Fettsäuren der Cerebroside, Sphingomyeline und Phosphatidyläthanolamine. Diese Veränderungen gegenüber gesunden Gehirnen werden als typische degenerative Erscheinungen interpretiert. In den mark-reichen Regionen finden sich neben typischen degenerativen Erscheinungen auch Verlängerungen der C-Kette der Fettsäuren in den Cerebrosiden und Sphingomyelinen und eine Zunahme der Polyensäuren in den Phosphatidyläthanolaminen. Diese Veränderungen werden als atypische Form der cerebralen Degeneration bezeichnet. Änderungen in der vorliegenden Art sind für andere Erkrankungen des Gehirnes bisher nicht beschrieben worden. - Die chemischen Veränderungen in den untersuchten Gehirnen korrelieren nicht mit dem Grad der histologischen Veränderungen, welche sehr gering sind. Es besteht jedoch eine gewisse Parallele zum klinischen Bild: alle untersuchten Patienten mit Hepatargie hatten ausgeprägte neurologische und psychische Symptome.

The brain lipids of patients who had died as a result of alcoholic cirrhosis showed distinct deviations from those in normal brains $(1-3)$. The decrease of the cerebrosides in all regions examined and the decline of the glycerophosphatides and cholesterol in the regions rich in white matter was conspicuous. Due to lack of information on the fatty acid composition of these lipids in "hepatocerebral degeneration", we extended the examination to this field.

\section{Material and Methods \\ Autopsy}

The autopsies were performed within 24 to $48 \mathrm{hrs}$ after death. All the material of the normal human brains was subjected to pathological-anatomical examinations and quantitative analysis of the main lipids. These were isolated only from material that showed no pathological changes. The brains examined of patients who died as a result of cirrhosis showed some macroscopic and microscopic changes, which have been described prevlously (3). The brains werc generally removed within 24 to $48 \mathrm{hrs}$ after death $(4,5)$, mainly because of legal problems. In several experiments we could show that within the first two days after death no changes occur in the lipids (LESCH, unpublished). The cerebrosides are also unchanged under autolytic conditions within 24 days post mortem (6).

\section{Degenerated brains}

The fatty acids of cerebrosides, sphingomyelins, phosphatidyl cholines and phosphatidyl ethanolamines of brains from patients aged 38-58 years who had died as a result of alcoholic cirthosis were examined. The patients had a 2 to 10 years history of excessive alcohol consumption. (The intake of 2 patients estimated at between 700 and $1500 \mathrm{~kg}$ of pure ethanol, and not less than $500 \mathrm{~kg}$ pure alcohol respectively.) Concerning the stationary treatment and clinical complications, see (3).

\section{Normal brains}

The fatty acids of the same major lipids of 6 normal brains from people aged between 50 and 80 years were examined. Their results have been published previously (7-9) and serve as a comparison with the present examination.

\section{Brain regions}

Within $48 \mathrm{hrs}$ of death $20-50 \mathrm{~g}$ of fresh tissue was taken from the following regions of the 6 brains, deep frozen, and kept at $-15^{\circ} \mathrm{C}$ to $-25^{\circ} \mathrm{C}$ until isolation and separation of the lipids:

grey matter (cortex) of cerebrum, white matter of cerebrum, cerebellum (grey and white matter mixed), medulla oblongata (and parts of pons).

\section{Lipids}

The isolation of total lipids and the separation of the individual lipids of normal and pathological brains was done in identical ways, with the same type of lipid separation columns and with the same organic solvents as are described in detail in previous publications $(3,9,10)$.

\section{Fatty acids}

The fatty acid methyl esters of the purc ccrebrosides, sphingomyelins and phosphatidyl cthanolamines were obtained through hydrolysis with $10 \%$ sulphuric acid in methanol $(10 \mathrm{ml}+90 \mathrm{ml})$. Each pure lipid, ca. $50 \mathrm{mg}$, was hydrolyzed with $5 \mathrm{ml}$ of $10 \%$ 
$\mathrm{H}_{2} \mathrm{SO}_{4}$ in methanol in a sealed tube for $5 \mathrm{hrs}$ in a boiling water bath. The tube was cooled to room temperature and opened, and the fatty acid methyl esters of phosphatidyl ethanolamines and sphingomyelins were extracted in the tube with 3 times $15 \mathrm{ml}$ of petrol ether (b. p. $50-70^{\circ} \mathrm{C}$ ) and the methyl esters of cerebrosides were extracted with 2 times $15 \mathrm{ml}$ of petrol ether and 2 times $20 \mathrm{ml}$ of diethyl ether. The combined extracts were rinsed with water, and than dried over anhydrous $\mathrm{Na}_{2} \mathrm{SO}_{4}$ overnight. The ether solutions were evacuated over an evaporator next day. Subsequently the tubes were placed over $\mathrm{P}_{2} \mathrm{O}_{5}$ in a dark vacuum desiccator and kept overnight again. During evaporation we gassed permanently and during evacuation we gassed several times with nitrogen prior to final evacuation. But several tests showed no decrease in values for polyenoic acids of phosphatidyl ethanolamines when the nitrogen gassing was omitted.

The fatty acid methyl esters of phosphatidyl cholines were obtained through mild alkaline methanolysis (11). To the tubes containing phosphatidyl cholines and sphingomyelins were added $0.22 \mathrm{ml} 0.5 \mathrm{~mol} / 1 \mathrm{CH}_{3} \mathrm{ONa}$ in dry methanol and $1.85 \mathrm{ml}$ dry chloroform: dry methanol 1:1 per $10 \mathrm{mg}$ lipid. The tubes were kept for $15 \mathrm{hrs}$ at room temperature. Subsequently to each $2.1 \mathrm{ml}$ lipid methoxide fraction $1.35 \mathrm{ml}$ dry chloroform was added. The solution was placed on a silica gel column $(7.5 \mathrm{~g}$ silica gel type 7734 E. Merck AG Darmstadt, Germany, for each $50 \mathrm{mg}$ lipid). The fatty acid methyl esters of phosphatidyl cholines could be separated promptly from the unchanged sphingomyelins with $200 \mathrm{ml}$ chloroform:methanol 2:1, whereas the latter were eluted with methanol (3). The chloroform:methanol solution was evaporated to dryness under a gentle stream of nitrogen. Owing to the contamination of this fraction containing the esters of phosphatidyl cholines we used another silica gel column $(10 \mathrm{~g}$ type 7734 for $100-200 \mathrm{mg}$ esters) and eluted the pure methyl esters with a solution of petrol ether (b. p. $50-70^{\circ} \mathrm{C}$ ): diethyl ether 1:1. The latter extract was evaporated to dryness on a water bath at $30^{\circ} \mathrm{C}$ under a gentle stream of nitrogen. These tubes were also placed over $\mathrm{P}_{2} \mathrm{O}_{5}$ in a vacuum desiccator which was promptly evacuated and kept overnight.

The sphingomyelins were purified as published previously (3).

The fatty acid methyl esters of phosphatidyl cholines, phosphatidyl ethanolamines and sphingomyelins were then ready for analysis by gas liquid chromatography. The cerebrosides, however, had to be first separated on an activated silica gel column into the unsubstituted and 2-monohydroxy components. Originally this was done with the $10 \% \mathrm{AgNO}_{3}$-silica gel column and gradient elution described previously (12-14). Later we developed a simpler method, which we have not described and which, after several tests, showed no difference of concentration of unsubstituted and hydroxy fatty acid methyl esters of cerebrosides of normal brains in comparison to the published method (14). This separation method, however, contrary to the $\mathrm{AgNO}_{3}$-silica gel column method, did not permit separation into saturated and unsaturated fatty acids, but only into unsubstituted and substituted acids: For $100-200 \mathrm{mg}$ cerebroside fatty acid methyl esters we used $30 \mathrm{~g}$ silica gel (type $7734 \mathrm{E}$. Merck AG).

Using a column of $1.6 \mathrm{~cm} \mathrm{I}$. D., the unsubstituted methyl esters were obtained by passing $300 \mathrm{ml}$ ethanol-free, amylene-stabilized chloroform (Chemische Werke Hüls AG, Marl); the hydroxy fatty acid methyl esters were then obtained by passing $200 \mathrm{ml}$ dry chloroform: dry diethyl ether 10:1.

The hydroxy group of the 2-hydroxy fatty acid methyl esters were etherified with $\mathrm{Ag}_{2} \mathrm{O}$ and $\mathrm{CH}_{3} \mathrm{~J}$ on a water bath at $56^{\circ} \mathrm{C}$ under a gentle stream of nitrogen over $3 \mathrm{hrs}$ (15). At first $40 \mathrm{mg} \mathrm{Ag}_{2} \mathrm{O}$ and $2 \mathrm{ml} \mathrm{CH}_{3} \mathrm{~J}$ were added to $10 \mathrm{mg}$ of hydroxy fatty acid mixture. After 30 and $60 \mathrm{~min}$ the addition of the same amounts of silver oxide and methyl iodide was repeated, the latter only if necessary. After filtration and evaporation, the methyl ethers of the methyl esters of cerebrosides were also ready for the gas liquid chromatography.

\section{Gas liquid cbromatograpby}

The methyl esters were analyzed by gas liquid chromatography in a Perkin Elmer model 801 or 900 apparatus with flame ionization detector. A $180 \mathrm{~cm}$ glass column of $3.6 \mathrm{~mm}$ I.D. packed with $2.5 \%$ diethylene glycol succinate polyester (DEGS) coated on 80-100 mesh Chromosorb $G$ was used for the fatty acid methyl esters of the two glycerophosphatides, and $2 \%$ Silicone (SE-52) coated on 80-120 mesh Chromosorb $G$ was used for the fatty acids of the neutral sphingolipids. The flow rate was $30 \mathrm{ml}$ of double purified nitrogen per minute at an inlet pressure of 50 pounds/inch ${ }^{2}$. The column temperature of the DEGS column was $180^{\circ} \mathrm{C}$ at the start; 10 min after injection we started a temperature elevation of $2^{\circ} \mathrm{C}$ per minute up to $200^{\circ} \mathrm{C}$ at the end. The column temperature of the SE-52 column was $220^{\circ} \mathrm{C}$ at the start. Ten minutes after injection we started a temperature program of $2^{\circ} \mathrm{C}$ per minute up to $250^{\circ} \mathrm{C}$ at the end. The quantitative recoveries from each column were determined with NIH fatty acid standards or own standards, the latter are being mainly phospholipid fatty acid esters from bull testis and whale or dolphin brains, which are determined with threefold gas liquid rechromatography, iodine number, infra red, ultra violet, and mass spectrometry.

Using these methods it was possible to identify fatty acid methyl esters as C-20:2 $\omega 9, C-20: 3 \omega 6$ and $-\omega 9, C-22: 2 \omega 6$ and $-\omega 9$, $C-22: 3 \omega 6$ and $-\omega 9, C-22: 5 \omega 3$ and $-\omega 6$.

The quantitative results agreed with the statè composition data with a relative error of less than 2 to $3 \%$ for major components and less than 4 to $6 \%$ for minor peaks.

The gas liquid chromatographic analysis of fatty acid methyl esters of normal and pathological brains were done in the same manner as described previously for normal brains (references see (9)). Comparison of the results from the gas liquid chromatographic apparatuses, which were used, showed a very good similiarity. The unique problematic difference between both apparatuses, however, seems to be a slightly higher sensitivity of the FID of the Perkin Elmer model 900 for polyenoic acids ranging between 2 and $4 \%$ of the sum of polyunsaturated components of each individual glycerophosphatide fatty acid mixture in the normal brains.

The individual esters were identified by comparison with internal standards whenever feasible but recently only with the aid of a diagram of $\log$ retention time and $\mathrm{C}$-number which has been described by ACKMan et al. (16). In both sphingolipids of pathological brains examined, however, we regularly found peaks $(x 1-x 13)$ in the gas liquid chromatographic analysis on the SE-52 column which at first could not be identified in the diagram of ACKMAN and which have been not found in fatty acids of sphingolipids of normal brains. Using mass spectrometry it was possible to identify the peaks $\times 6$ and $\times 8$ as polyenoic acids (17) and $x 3$ and $x 5$ as contaminations of the silica gel used and $x 7$ as a contamination of the filter papers (Schleicher \& Schüll paper $589^{3}$ and $15741 / 2$ ) which have been extracted twice with organic solvents before using. There contaminants have been identified previously (18).

\section{Results}

The yield of fatty acid methyl esters obtained by hydrolysis or esterification lies at $35-42 \%$ for the sphingolipids, and for the 2 glycerophosphatides at roughly $65-72 \%$ of the lipids. Compared with the total lipids, the content of methyl esters of the glycerophosphatides in the grey matter is 1.5 to 2 times as high as in the areas rich in white substance (white matter and medulla oblongata). Referring to the fresh weight, however, the highest content of total fatty acids was found in white matter and medulla (Tab: 1). The amounts of methyl esters are less in the brains of patients with alcohol-related liver cirrhosis than in the normal brains. The decrease of fatty acids corresponds to the diminished lipid content of the "hepatogenic degenerated" brains as opposed to the normal brains. 
Tab. 1

Fatty acid methyl esters of cerebrosides, sphingomyelins, phosphatidyl cholines and phosphatidyl ethanolamines in $\mu$ mol/g fresh weight of brains with alcohol-related hepatogenic degeneration

\begin{tabular}{|c|c|c|c|c|}
\hline \multirow[t]{2}{*}{ Fatty acid methyl esters } & \multicolumn{2}{|c|}{ Cerebrum } & \multirow[t]{2}{*}{ Cerebellum } & \multirow{2}{*}{$\begin{array}{c}\text { Medulla } \\
\text { oblongata }\end{array}$} \\
\hline & grey matter & white matter & & \\
\hline Cerebrosides, total & 4.20 & 25.28 & 9.48 & 22.30 \\
\hline Cerebrosides, 2-monohydroxy & 1.60 & 10.97 & 4.72 & 10.79 \\
\hline Sphingomyelins, total & 3.33 & 11.13 & 5.59 & 10.53 \\
\hline Phosphatidyl cholines, total & 21.02 & 30.86 & 25.46 & 31.41 \\
\hline Phosphatidyl ethanolamines, total & 18.63 & 40.36 & 27.01 & 42.97 \\
\hline \multicolumn{5}{|l|}{ Sum of fatty acid methyl esters } \\
\hline in brains from alcoholics $(n=6)$ & 47.18 & 107.63 & 67.54 & 107.21 \\
\hline \multicolumn{5}{|l|}{ Sum of fatty acid methyl esters } \\
\hline in normal brains $(n=6)$ & 68.12 & 133.68 & 103.02 & 155.62 \\
\hline
\end{tabular}

Tab. 2

Unsubstituted fatty acid composition of sphingolipids of brains with alcohol-related hepatogenic degeneration Mean values $(n=6)$ are weight percentages of total unsubstituted fatty acid methyl esters of cerebrosides and sphingomyelins. The following components (acids and unidentified substances, e. g. $\times 7$ ) were detected in small amounts (in general less than 1\%): 14:1, 15:0, 15:1, 17:0, 17:1, $19: 0,19: 1,20: 1,21: 0,21: 1, \times 1-\times 5, \times 7, \times 9-\times 13.14: 0=$ fatty acids are denoted by chain length:number of double bonds

\begin{tabular}{|c|c|c|c|c|c|c|c|c|}
\hline \multirow[t]{3}{*}{ Fatty acids } & \multicolumn{4}{|c|}{ Cerebrosides } & \multicolumn{4}{|c|}{ Sphingomyelins } \\
\hline & \multicolumn{2}{|c|}{ Cerebrum } & \multirow[t]{2}{*}{ Cerebellum } & \multirow{2}{*}{$\begin{array}{l}\text { Medulla } \\
\text { oblongata }\end{array}$} & \multicolumn{2}{|c|}{ Cerebrum } & \multirow[t]{2}{*}{ Cerebellum } & \multirow{2}{*}{$\begin{array}{c}\text { Medulla } \\
\text { oblongata }\end{array}$} \\
\hline & grey matter & white matter & & & grey matter & white matter & & \\
\hline $14: 0$ & 1.7 & 0.6 & 1.2 & 0.5 & 0.8 & 0.3 & 0.3 & 0.3 \\
\hline $16: 0$ & 8.3 & 3.2 & 4.8 & 3.1 & 4.3 & 3.6 & 5.1 & 3.3 \\
\hline $16: 1$ & 1.4 & 0.3 & 0.7 & 0.3 & 0.8 & 0.3 & 0.5 & 0.3 \\
\hline $18: 0$ & 18.5 & 8.2 & 11.7 & 10.2 & 57.9 & 27.0 & 47.0 & 33.4 \\
\hline $18: 1$ & 10.6 & 3.4 & 6.3 & 2.7 & 2.4 & 1.7 & 2.1 & 1.8 \\
\hline$\times 6$ & 1.8 & 0.2 & 0.6 & 0.2 & 0.2 & 0.1 & 0.1 & 0.1 \\
\hline $20: 0$ & 1.6 & 0.9 & 1.1 & 0.9 & 3.2 & 1.3 & 3.0 & 1.4 \\
\hline$\times 8$ & 4.5 & 0.6 & 2.0 & 0.6 & 0.6 & 0.2 & 0.3 & 0.2 \\
\hline $22: 0$ & 1.5 & 2.0 & 1.6 & 2.2 & 1.5 & 1.7 & 1.1 & 1.9 \\
\hline $22: 1$ & 1.2 & 0.7 & 0.8 & 0.7 & 1.2 & 0.8 & 0.6 & 0.7 \\
\hline $23: 0$ & 1.5 & 3.3 & 2.5 & 3.1 & 1.0 & 2.3 & 1.5 & 1.9 \\
\hline $23: 1$ & 1.2 & 1.1 & 0.9 & 0.9 & 0.8 & 1.1 & 0.9 & 0.9 \\
\hline $24: 0$ & 5.1 & 11.1 & 9.1 & 12.5 & 2.5 & 7.5 & 4.7 & 6.3 \\
\hline $24: 1$ & 17.8 & 38.0 & 29.5 & 38.5 & 8.7 & 32.8 & 17.5 & 31.6 \\
\hline $25: 0$ & 1.8 & 4.2 & 3.9 & 3.8 & 1.1 & 2.8 & 1.5 & 2.0 \\
\hline $25: 1$ & 6.4 & 9.4 & 8.1 & 7.4 & 2.2 & 6.3 & 4.4 & 4.1 \\
\hline $26: 0$ & 0.6 & 0.8 & 0.6 & 0.8 & 0.4 & 0.6 & 0.4 & 1.1 \\
\hline $26: 1$ & 4.4 & 7.7 & 6.4 & 6.9 & 1.5 & 5.0 & 3.3 & 3.9 \\
\hline \multicolumn{9}{|l|}{ Totals } \\
\hline saturated & 43.3 & 35.2 & 38.0 & 38.0 & 74.6 & 48.2 & 66.3 & 53.0 \\
\hline unsaturated & 46.4 & 61.3 & 55.0 & 58.5 & 20.3 & 49.1 & 30.9 & 44.5 \\
\hline$(\times 1-x 13)$ & 10.3 & 3.5 & 7.0 & 3.5 & 5.0 & 2.7 & 2.8 & 2.5 \\
\hline
\end{tabular}

The unsubstituted fatty acids of the cerebrosides (Tab. 2)

From dodecanoic acid to hexacosenic acid all saturated and mono-unsaturated even and odd numbered acids were present, but some only in traces. The main components were those with 18 and $24 \mathrm{C}$-atoms. Palmitic, penta- and hexacosanoic acid accounted for 3-9\%, depending on the region. In all regions of the brain from alcoholics the concentration of stearic acid was lower than in the normal brain (Tab. 3). Nevertheless, the concentration of long chain acids (C-24 and C-26) was higher, except in the grey matter. The portion of acids with a chain length of up to $20 \mathrm{C}$-atoms amounted, on the average, to only $20-30 \%$.
The 2-hydroxy fatty acids of the cerebrosides (Tab. 4)

All the components with an even and odd numbered chain between hydroxy-dodecanoic acid and hydroxyhexacosanoic acid were also found in this fraction. Apart from the cerebronic and hydroxy-nervonic acids, the components with $22,23,25$ and 26 C-atoms were present in the highest concentrations. The proportion of acids with less than $20 \mathrm{C}$-atoms was $10 \%$ for the grey matter and $5 \%$ for the white matter (Tab. 5 ).

The fatty acids of sphingomyelins (Tab. 2) $30 \%$ of both stearic and nervonic acid were found in the white matter and medulla oblongata, while in the 


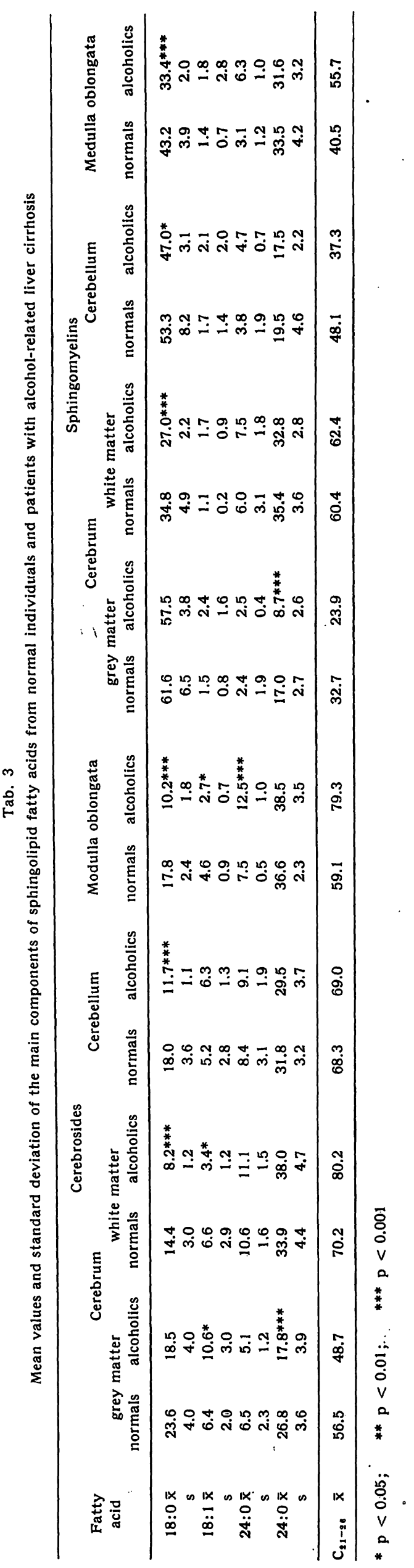

Tab. 4

2-Hydroxy fatty acid composition of the cerebrosides of brains with alcohol-related hepatogenic degeneration

Mean values $(n=6)$ are weight percentages of total hydroxy fatty acid methyl esters of cerebrosides. The following were detected in small amounts (in general less than $1 \%$ ): $14 \mathrm{~h}: 1,15 \mathrm{~h}: 0,15 \mathrm{~h}: 1$, $17 \mathrm{~h}: 0,17 \mathrm{~h}: \mathrm{l}, 18 \mathrm{~h}: 1,19 \mathrm{~h}: 0,19 \mathrm{~h}: 1,20 \mathrm{~h}: 1,21 \mathrm{~h}: 1,22 \mathrm{~h}: 1$. $14 \mathrm{~h}: 0=$ hydroxy fatty acids are denoted by chain length: number of double bonds

\begin{tabular}{ccccc}
\hline Fatty acid & \multicolumn{2}{c}{ Cerebrum } & Cerebellum & $\begin{array}{c}\text { Medulla } \\
\text { oblongata }\end{array}$ \\
& matter & $\begin{array}{c}\text { white } \\
\text { matter }\end{array}$ & & \\
\hline $14 \mathrm{~h}: 0$ & 2.5 & 0.3 & 0.9 & 0.6 \\
$16 \mathrm{~h}: 0$ & 2.1 & 0.5 & 1.2 & 0.8 \\
$16 \mathrm{~h}: 1$ & 1.1 & 0.4 & 0.8 & 0.5 \\
$18 \mathrm{~h}: 0$ & 0.8 & 0.6 & 0.9 & 1.2 \\
$20 \mathrm{~h}: 0$ & 1.0 & 0.4 & 0.4 & 0.5 \\
$21 \mathrm{~h}: 0$ & 3.0 & 1.3 & 1.7 & 1.0 \\
$22 \mathrm{~h}: 0$ & 5.3 & 5.3 & 5.7 & 6.8 \\
$23 \mathrm{~h}: 0$ & 11.3 & 12.9 & 12.3 & 13.0 \\
$23 \mathrm{~h}: 1$ & 2.2 & 1.4 & 1.2 & 0.9 \\
$24 \mathrm{~h}: 0$ & 26.9 & 28.3 & 29.6 & 32.0 \\
$24 \mathrm{~h}: 1$ & 20.0 & 27.9 & 21.4 & 22.4 \\
$25 \mathrm{~h}: 0$ & 6.2 & 5.6 & 6.4 & 5.7 \\
$25 \mathrm{~h}: 1$ & 5.4 & 4.7 & 5.4 & 4.3 \\
$26 \mathrm{~h}: 0$ & 1.3 & 1.0 & 1.7 & 1.4 \\
$26 \mathrm{~h}: 1$ & 7.1 & 6.5 & 6.8 & 6.3 \\
\hline
\end{tabular}

regions with predominant grey matter the stearic acid showed a 3-6 times higher concentration than the nervonic acid. The proportion of both these main components also corresponded to the sum of the fatty acid methyl esters with more than 21 C-atoms (Tab. 3): in the grey matter and cerebellum the amount of the acids with more than $21 \mathrm{C}$-atoms was considerably smaller $(20-40 \%)$ than in the areas rich in white substance, where it was roughly $60 \%$. The differences between these two groups are highly significant.

The fatty acids of the phosphatidyl cholines (Tab. 6):

The main components are palmitic and oleic acid followed by stearic acid. Only in the white matter and medulla oblongata did the proportion of oleic acid exceed that of the palmitic acid. The content of polyenoic acids in the 4 regions averaged $10 \%$ of which the arachidonic acid was the most important.

The fatty acids of the phosphatidyl ethanolamines (Tab. 6):

As with the phosphatidyl cholines the main components of the phosphatidyl ethanolamines were the acids with 16 and $18 \mathrm{C}$-atoms; there were significant differences between the regions of grey matter and the cerebrum on one side and the areas of white matter and the medulla oblongata on the other. In all 4 regions the amount of polyenoic acids was approximately equal. However, there were clear differences between the brain parts in the distribution of the single components. In the parts rich in grey matter, the arachidonic acid and docosahexaenoic acid prevailed, and in the regions rich in white substance, docosatetraenoic acid was predominant. 
Tab. 5

Mean values and standard deviation of the main components of cerebroside 2-hydroxy fatty acids from normal individuals and patients with alcohol-related liver cirrhosis

\begin{tabular}{|c|c|c|c|c|c|c|c|c|}
\hline \multirow{3}{*}{ Fatty acid } & \multicolumn{4}{|c|}{ Cerebrum } & \multicolumn{2}{|c|}{ Cerebellum } & \multicolumn{2}{|c|}{ Medulla oblongata } \\
\hline & \multicolumn{2}{|c|}{ grey matter } & \multicolumn{2}{|c|}{ white matter } & \multirow[b]{2}{*}{ normals } & \multirow{2}{*}{ alcoholics } & \multirow[b]{2}{*}{ normals } & \multirow[b]{2}{*}{ alcoholics } \\
\hline & normals & alcoholics & normals & alcoholics & & & & \\
\hline s & 2.5 & 1.3 & 2.0 & 2.8 & 2.1 & 0.5 & 1.7 & 0.9 \\
\hline $24 \mathrm{~h}: 0 \bar{x}$ & 23.9 & 26.9 & 26.8 & 28.3 & 30.1 & 29.6 & 26.6 & $32.0^{*}$ \\
\hline $\mathbf{s}$ & 2.8 & 3.3 & 4.5 & 7.0 & $\mathbf{3 . 0}$ & 3.1 & 4.1 & 3.7 \\
\hline $24 h: 1 \bar{x}$ & 27.6 & $20.0 * * *$ & 30.4 & 27.9 & 27.2 & $21.4^{*}$ & 30.2 & $22.4 * * *$ \\
\hline $\mathbf{s}$ & 3.4 & 2.1 & 8.4 & 5.9 & 5.1 & 3.1 & 2.3 & 3.7 \\
\hline $26 h: 1 \bar{x}$ & 5.7 & 7.1 & 4.3 & 6.5 & 4.0 & $6.8 * *$ & 4.0 & $6.3^{* *}$ \\
\hline $\mathbf{s}$ & 1.1 & 1.4 & 0.9 & 2.8 & 0.9 & 0.9 & 0.7 & 0.7 \\
\hline$C_{21-2 n} \bar{x}$ & 92.6 & 90.5 & 94.9 & 95.0 & 94.4 & 93.4 & 93.8 & 94.7 \\
\hline
\end{tabular}

$* \mathrm{p}<0.05 ; \quad * * \mathrm{p}<0.01 ; \quad * * * \mathrm{p}<0.001$

Tab. 6

Fatty acid composition of 2 glycerophosphatides of brains with alcohol-related hepatogenic degeneration Mean values $(n=6)$ are weight percentages of total fatty acid methyl esters of each glycerophosphatide. The following (except polyenes) were detected in small amounts (in general less than $1 \%$ ): 12:0,13:0,14:1,15:0,15:1, 17:0,17:1, 20:0

\begin{tabular}{|c|c|c|c|c|c|c|c|c|}
\hline \multirow[t]{3}{*}{ Fatty acid } & \multicolumn{4}{|c|}{ Phosphatidyl cholines } & \multicolumn{4}{|c|}{ Phosphatidyl ethanolamines } \\
\hline & \multicolumn{2}{|c|}{ Cerebrum } & \multirow{2}{*}{ Cerebellum } & \multirow{2}{*}{$\begin{array}{l}\text { Medulla } \\
\text { oblongata }\end{array}$} & \multicolumn{2}{|c|}{ Cerebrum } & \multirow{2}{*}{ Cerebellum } & \multirow{2}{*}{$\begin{array}{c}\text { Medulla } \\
\text { oblongata }\end{array}$} \\
\hline & grey matter & white matter & & & grey matter & white matter & & \\
\hline $14: 0$ & 1.2 & 1.1 & 1.1 & 0.9 & 0.8 & 0.9 & 0.5 & 0.8 \\
\hline $16: 0$ & 43.3 & 31.0 & 44.6 & 33.1 & 12.3 & 18.2 & 13.6 & 15.6 \\
\hline $16: 1$ & 2.9 & 2.1 & 2.5 & 2.3 & 1.1 & 0.7 & 1.0 & 0.7 \\
\hline $18: 0$ & 9.5 & 9.8 & 8.0 & 9.1 & 31.7 & 7.5 & 19.2 & 10.9 \\
\hline $18: 1$ & 29.8 & 45.3 & 32.0 & 42.7 & 17.2 & 33.8 & 26.0 & 31.2 \\
\hline $18: 2$ & 0.9 & 0.7 & 0.8 & 0.9 & 0.3 & 0.5 & 0.5 & 0.9 \\
\hline $18: 3$ & 0.8 & 0.3 & 0.4 & 0.7 & 0.5 & 1.5 & 0.9 & 1.2 \\
\hline $20: 1$ & 0.1 & 2.1 & 0.5 & 1.8 & 2.7 & 8.1 & 4.4 & 10.8 \\
\hline $20: 2 \omega 9$ & 0.3 & 0.3 & 0.3 & 0.3 & 1.0 & 1.0 & 0.8 & 0.9 \\
\hline $20: 3 \omega 9$ & 0.8 & 0.3 & 0.3 & 0.5 & 0.3 & 0.7 & 0.7 & 1.6 \\
\hline $20: 3 \omega 6$ & 0.2 & 0.2 & 0.5 & 0.3 & 0.3 & 0.6 & 0.1 & 0.6 \\
\hline $20: 4$ & 2.9 & 1.3 & 2.8 & 1.6 & 6.7 & 4.5 & 6.8 & 4.4 \\
\hline $20: 5$ & 0.1 & 0.1 & 0.1 & 0.1 & 0.4 & 0.4 & 0.2 & 0.4 \\
\hline $22: 2 \omega 9$ & 0.1 & 0.3 & 0.6 & 0.5 & 0.9 & 0.3 & 0.2 & 0.2 \\
\hline $22: 3 \omega 9$ & 0.2 & 0.2 & 0.1 & 0.1 & 0.2 & 0.4 & 0.2 & 0.6 \\
\hline $22: 3 \omega 6$ & 0.2 & 0.2 & 0.2 & 0.3 & 0.6 & 0.9 & 0.4 & 0.6 \\
\hline $22: 4$ & 1.0 & 0.9 & 0.6 & 0.8 & 6.9 & 12.0 & 6.8 & 9.0 \\
\hline $22: 5 \omega 6$ & 0.2 & 0.1 & 0.3 & 0.2 & 1.3 & 0.6 & 0.8 & 0.8 \\
\hline $22: 5 \omega 3$ & 0.4 & 0.4 & 0.4 & 0.2 & 0.9 & 0.5 & 0.7 & 0.8 \\
\hline $22: 6$ & 3.0 & 1.6 & 2.4 & 2.1 & 11.6 & 4.6 & 14.3 & 5.7 \\
\hline \multicolumn{9}{|l|}{ Totals } \\
\hline saturated & 55.1 & 42.7 & 54.6 & 43.9 & 46.4 & 27.1 & 34.0 & 27.8 \\
\hline monoenes & 33.1 & 50.0 & 35.3 & 47.2 & 19.3 & 36.3 & 28.2 & 33.4 \\
\hline polyenes & 11.8 & 7.3 & 10.1 & 8.9 & 35.0 & 37.2 & 38.4 & 37.3 \\
\hline
\end{tabular}

\section{Discussion}

Normal variations with age

During the course of myelination and maturation quantitative changes occur in the lipids, including the fatty acids. In the sphingolipids the very long acids increase $(19-24)$. In the glycerophosphatides $(5,23$, $25-28)$ and cholesterol esters $(29,30)$ the proportion of palmitic acid increases, while in the phosphatidyl ethanolamines oleic acid increases at the expense of stearic acid. The relative proportion of the polyenoic acids up to docosahexaenoic acid remains fairly constant in the grey matter and thalamus $(25,28)$ and is reduced in the white matter (5). It is known that during ageing there is a discreet regression of fatty acids, especially of the components with more than $24 \mathrm{C}$-atoms in the grey and white matter (9).

This slight drop of the very long acids in the physiological ageing process is not significant and has not been related to histological changes. A relative decrease of the very long fatty actds and a relative increase of the palmitic and stearic acid become significant only when senile brain lesions show morphological differences compared with normal brains (31).

\section{Pathological variations}

The process of the fatty acid diminution is accelerated many times when pathological changes exist (32). Simultaneously there is an intensified loss of the poly- 
enoic acids (33-35). These changes in the lipid and fatty acid pattern are assumed to be the signs of typical degenerative demyelinization as described and discussed elsewhere (32).

\section{The fatty acids of neutral spbingolipids}

In brains that we examined of patients showing alcohol-toxic cirrhosis with neurological and mental symptoms, the changes in the fatty acid samples correlate partly with those described above. The decrease of the cerebrosides in all 4 regions (3) and the glycerophosphatides in the regions rich in white substance points to a degenerative process. The decrease of nervonic and hydroxynervonic acid in the sphingolipids of the grey matter and the decline of docosahexaenoic, arachidonic and stearic acid with the simultaneous rise of palmitic acid in the phosphatidyl ethanolamines of the grey matter fits into this picture.

Other changes, however, in the fatty acid array differed from those described as typical for degeneration.

In the unsubstituted fatty acids of the cerebrosides there was no decrease in the very long components in all 4 regions, but only a decline of the stearic acid. In the grey matter the loss of stearic acid coincided with a significant rise of oleic acid and, in the regions rich in white substance, with a slight rise of nervonic acid. Altogether the proportional increase of the fatty acids with more than $21 \mathrm{C}$-atoms in the white matter and medulla oblongata was comparable with that in normal brains (Tab. 3).

Compared with normal brains, the hydroxy fatty acids of the cerebrosides showed a small decrease of the hydroxytetracosenic and an increase of the hydroxyhexacosenic acid (Tab. 5) in the 4 regions; no other differences were demonstrated.

Also in all 4 areas the stearic acid of the sphingomyelins was diminished. In the regions rich in white substance, however, the acids with $22,23,25$ and $26 \mathrm{C}$-atoms were slightly increased (column " $\mathrm{C}_{21-26} \overline{\mathrm{x}}$ " Tab. 3). In the "white" tissue a slight chain lengthening was found, whereas the changes in the grey matter resembled those found in degeneration $(32,36)$.

The fatty acids of the cerebrosides and sphingomyelins show a similar pattern due to their similar synthesis and precursors (37). The synthesis and oxidation appear to proceed in parallel and result in a displacement of the fatty acid pattern in the white matter and medulla oblongata, compared to healthy brains.

The result would be lowering of the lipid content, compared with normal brains, i. e. degeneration. Secondly, it seems that with a possible UDP-hexose deficiency (38) or an enzyme inhibition, the cerebrosides "over-age" because of a lack of de-novo-synthesis; this is seen in the increasing concentration of very long acids in these sphingolipids.

\section{The fatty acids of glycerophosphatides}

In the phosphatidyl cholines the fatty acid pattern of the pathological brains corresponded exactly to that

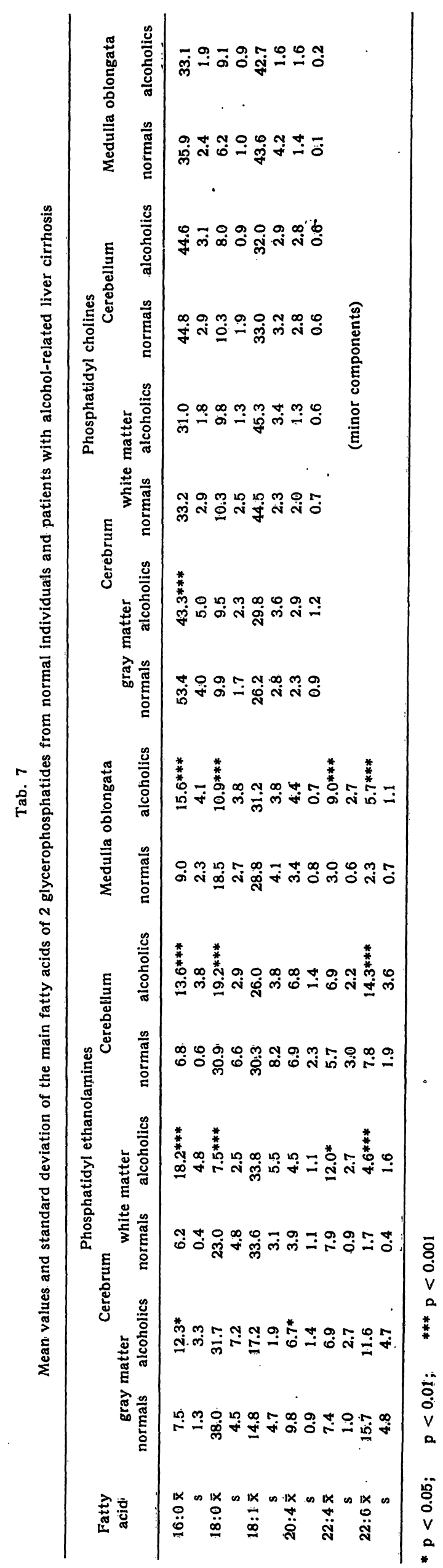

Z. Klin. Chem. Klin. Biochem/ 11. Jahrg. 1973/ Heft 4 
of the normal brains. The only exception was the palmitic acid, which was clearly lower in the grey matter of the pathological brains.

The striking changes of the fatty acids in the phosphatidyl ethanolamines were of two kinds: firstly a generalized decrease of the stearic acid and increase of the palmitic acid was found. The decrease of the chain length was one of the above mentioned features of ontogenetic brain degeneration.

However, the changes of the polyenoic acid composition of the phosphoglycerides must be interpreted in a different way. The typical decrease of the polyenes $(5,33,35)$ seen in the degeneration, could not be found in the brains of alcoholics. On the contrary, in the white matter and medulla oblongata the proportion of docosatetraenoic and docosahexaenoic acid was clearly higher than in the normal brains. The increase of the sum of total polyenoic acids in the respective regions can also clearly be seen (not demonstrated in a table).

Are the changes in the brain in alcohol abuse caused directly by the influence of alcohol or through a metabolite of ethanol? Or do the changes first appear as a result of the pathological metabolism in alcohol-related liver cirrhosis?

Reasons for cerebral degeneration: alcohol or liver damage?

Acute and chronic alcohol abuse result in a peripheral lipolysis with hyperlipacidemia $(39,40)$ followed by supersaturation of the liver with rising hepatic fatty acid synthesis (41) and decrease of fatty acid oxidation (42). The increased hepatic triglyceride synthesis from the acids of the depot fat is accompanied by a diminished insertion of the fatty acids into the phosphatides (43). Furthermore, the lipoprotein lipase activity is diminished by ethanol $(44,45)$ which can only result in a further supply of alimentary fat to the liver. This is further aggravated by any existing dietary lack of protein (46).

MARCINIAK et al. (48) found, after giving dogs about $100 \mathrm{~g}$ ethanol per day over a period of 10 weeks, a significant elevation of glycerides in liver, heart and serum and an insignificant increase of glycerides in the brain. The glycerides were determined separately from the glycerophosphatides. This was the only indication known to us of experimentally created lipid changes in the brain after alcohol consumption. However, we never found a high concentration of glycerides in normal or pathological brains.

In ethanol-related cirrhosis the total fatty acids in the serum differ from those of healthy controls (47): There is a slight rise in palmitoleic and oleic acid and a slight decrease in linoleic and arachidonic acid. These changes indicate a disturbed lipid metabolism, but according to our observations have no influence on the fatty acid composition in the brain.

We could not find any reference that the changes of lipid and fatty acid composition in liver and adipose tissue in patients with alcoholic liver cirrhosis do have an immediate influence on the fatty acid composition of the brain. In none of the brain regions examined we could find an indication that, due to lipolysis, more free fatty acids from the depots were reaching the brain, and the phosphoglycerides in particular. This would confirm the assumption of SPERRY et al. $(49,50)$ that the transport of saturated fatty acids into adult mammalian brain is restricted by the blood-brainbarrier.

Ethanol can lead to the Wernicke-Korsakoff syndrome when consumed over a long period of time or in large amounts without the accompaniment of a liver impairment. Acute alcohol intake causes a reduction of the blood flow to the brain, a diminished cerebral oxygen consumption and glucose turn-over (51) and a diminution of the glycogen content in the brain (52), probably as a result of increased liberation of catecholamines from the adrenal medulla. These results are correlated anatomically by a completely different observation: in alcoholics the third ventricle of the brain is significantly widened (53) and the young brain seems to be especially affected. The echoencephalographically measured brain atrophy, possibly related particularly to the cortex, is an anatomic sign of the degeneration.

Is the lowered brain metabolism in the chronic drinker the biochemical equivalent of cortical atrophy? A possible answer is our observation that in patients with alcoholic toxic cirrhosis the lipid and fatty acid concentration in the brain is significantly decreased.

However, in liver insufficiency there is a rise of armonia, free phenol and their derivatives (54), methyl guanidine and free fatty acids (55) in the serum. Today less importance is given than previously to the high $\mathrm{NH}_{3}$ in the blood $(56,57)$. Recently it has been proved that at least in healthy persons, the brain (58) and skeletal muscle (59) metabolize as much ammonia as the liver.

The increase of the phenylcarbonic acids and the aromatic hydroxy acids in the blood which is characteristic for liver insufficiency, can lead to an accumulation of these in the brain (60), where they result in enzymatic changes (61) concerned with oxidative phosphorylation in the brain.

To summarize, it can be said that the cause of the cerebral degeneration in the alcohol-related liver cirrhosis is not clear. One thing, however, is certain: up to the present there has not been any proof that alterations in liver metabolism, as found in alcoholics, were the only cause of ethanolic "hepatocercbral degeneration". The direct toxic effects of alcohol may have just as much importance.

\section{Acknowledgements}

The authors acknowledge with gratitude the technical assistance of Miss P. Stacher and Miss G. Scherbe and the generous gift of chemicals from Chemische Wcrke I-Iüls, Marl. The study was supported in part by LVA Hannover and "Spenderkreis Toxische Leberschäden" Hannover. We also thank Mrs. Dr. I. ODENHeIMER (Basel) and C. M. Huston, MD (BHM Hannover) for help with the translation. 


\section{References}

1. LESCH, P. (1972), Klin. Wochenschr. 50, 269-270. - 2. LESCH, P. (1972), Klin. Wochenschr. 50, 663-665. - 3. LESCH, P., Schmidt, E. \& Schmidr, F. W. (1972), this journal 10; 410-415. 4. Rouser, G., Kritchevsky, G. Siakotos, A. N. \& Yamamoto, A. (1970), in Neuropathology - Methods and Diagnosis (TEDESCHI, C. G., ed.), p. 691-753, Little, Brown \& Co., Inc. New York N. Y. - 5. Svennerholm, L. (1968), J. Lipid Res. 9, 570-579. - 6. Leube, C. \& Lindlar, F. (1971), Hoppe-Seyler's Z. physiol. Chem. 352, 1100-1104. - 7. LesCh, P. \& MeIER, S. (1964), Klin. Wochenschr. 42, 799-802. - 8. LESCH, P., MEIER, S. \& Bernhard, K. (1966), Helv. Chim. Acta 49, 791-797. 9. LesCH, P. (1969), Clin. Chim. Acta 25, 269-283. -10. BerNhard, K., Lesch, P. \& Neuhaus-Merer, S. (1969), Helv. Chim Acta 52, 1815-1822. - 11. Kishimoto, Y. \& Radin, N. S. (1959), J. Lipid Res. 1, 62-71. - 12. DE VRIEs, B. (1963), J. Amer. Oil Chem. Soc. 40, 184-186. - 13. DE VRIES, B. (1964), J. Amer. Oil. Chem. Soc. 41, 403-406. - 14. WAGNER, H., GOETSCHEL, J.-D. \& LesCH, P. (1963), Helv. Chim. Acta 46, 2986-2989. 15. Kishimoto, Y. \& Radin, N. S. (1959), J. Lipid Res. 1, 72-78. 16. Ackman, R. G., Burgher, R. D. \& JangaArd, P. M. (1963), Canad. J. Biochem. Physiol. 41, 1627-1641. - 17. LesCH, P. \& Remberg, G. (1973), Klin. Wochenschr. 51, 133-136. - 18. Unruh, G. v., Remberg, G. \& Spitteler, G. (1971), Chem. Ber. 104, 2071-2078. - 19. Bernhard, K., Hany, A., Hausheer, L. \& Pedersen, W. (1962), Helv: Chim. Acta 45, 1786-1794. 20. Kishimoto, Y., Davies, W. E. \& Radin, N. S. (1965), J. Lipid Res. 6, 525-531. - 21. Kishimoto, Y. \& RAdiN, N. S. (1966), Lipids 1, 47-61. - 22. Menkes, J. H., Philippart, M. \& Concone, M. C. (1966), J. Lipid Res. 7, 479-486. - 23. O'Brien, J. S. \& Sampson, E. L. (1965), J. Lipid Res. 6, 545-551. 24. Ställberg-Stenhagen, S. \& Svennerholm, L. (1965 \& 1968), J. Lipid Res. 6, 146-155 and 9, 215-221. -25. Altrock, K. \& DeBuch, H. (1968), J. Neurochem. 15, 1351-1359. 26. Hansen, I. B. \& Clauusen, J. (1968), Scand. J. Clin. Lab. Invest. 22, 231-238. - 27. LESCH, P. \& BERNHARD, K. (1965), Helv. Physiol. Acta 23, C 101. - 28. Skribc, T. R. \& Cummings, J. N. (1970), J. Neurochem. 17, 85-89. - 29. Alling, C. \& SvenNerholar, L. (1969), J. Neurochem. 16, 751-759. - 30. Eтo, Y. \& Suzuki, K. (1972), J. Neurochem. 19, 109-115. 31. Rouser, G., Feldman, G \& Galli, C. (1965), J. Amer. Oil Chem. Soc. 42, 411-412. - 32. Jatzkewitz, H. \& MeHL, E. (1962), Hoppe-Seyler's Z. physiol. Chem. 329, 264-277. 33. Gerstl, B., ENG, L. F., TAvaststjerna, M. G. \& Smith, J. K. (1970), J. Neurochem. 17, 677-689. - 34. Kamoshita, Y., Aron, A. M., Suzuki, K. \& Suzukr, K. (1969), Amer. J. Dis.
Child. 117, 379-394. - 35. Kishimoto, Y., Radin, N. S., Tourtelotte; W. W., Parker, J. A. \& Itabashi, H. H. (1967), Arch. Neurol. 16, 44-54. - 36. Gerstr, B., Hayman, R. B. \& Smiths, J. K. (1962), Experientia 18, 1318-1319. - 37. HAJRA, A. K. (1963), Metabolism of the Cerebroside Fatty Acids. Univ. Microfilms Inc., Anin Arbor, Mich., No. 64-5842. - 38. RAdrN, N. S. (1971), pers. communication. - 39. Fex, G. \& OliveCrona, T. (1969), Acta Physiol. Scand. 75, 78-81.1 - 40. Poggr, M. \& Luzio, N. R. (1964), J. Lipid Res. 5, 437-441. - 41. Lieber, C. S. \& SCHMID, R. (1961), J. Clin. Invest. 40, 394-399. 42. Reboucas, G. \& Isselbacher, K. J. (1961), J. Clin. Invest. 40, 1355-1362. - 43. Scheig, R. L. \& Isselbacher, K. J. (1963), J. Clin. Invest. 42, 975-976. - 44. Jones, D. P., LosowsKY, M. S., Davidson, C. S. \& Lieber, C. S. (1963), J. Clin. Invest. 42, 945-946. - 45. Robinson, D. S. \& SEAKINS, A. (1962), Biochim. Biophys. Acta 62, 162-169. - 46. Ammon, H. P. T. (1970), Acta hepato-splen. 17, 330-343. - 47. Marzo, A., Ghirardi, P., Sardini, D., Prandini, R. B. \& Albertini, A. (1970), Klin. Wochenschr. 48, 949-950. - 48. Marciniak, M., Gudbjarnason, S. \& Bruce, T. A. (1968), Pioc. Soc. Exp. Biol. Med. 128, 1021-1025. - 49. SPERRY, W. M., WaeLiSCH, H. \& Stoyanoff, V. A. (1940), J. Biol. Chem. 135, 281-290, 50. WAELSCH, H., SPERRX, W. M. \& STOYANOFF, V. A. (1940), J. Biol. Chem. 135, 291-299. - 51. ShimojyA, S., ScheinberG, P. \& Reinmuth, D. (1967), J. Clin. Invest. 46, 849-854. 52. Heim, F., Estler, C. J. \& Ammon, H. P. T. (1971), in: The Influence of Ethanol on Metabolism and Coenzymes of the Energy-producing Metabolism in Liver and Brain. In Metabolic Changes induced by Alcohol (Martini, G. A. \& Bode, C., ed.) p. 115-125, Springer, Berlin-Heidelberg-New York. - 53. Feuerlein, W. \& Heyse, H. (1970), Arch. Psychiatr. Nervenkrankh. 213, 78-85. - 54. RUGE, W. (1969), Untersuchungen über Serumspiegel und Urinausscheidung phenolischer Verbindungen bei Lebererkrankungen, Habilitations-Schrift Med. Hochschule Hannover 1969. - 55. Platzer, S., SaIler, S., SANDHOFER, F. \& BraunsteINER, H. (1966), Wien. Klin. Wochenschr. 78, 56-58. - 56. AsAO, H. \& OJI; K. (1968), Hepatocerebral Degeneration. Amer. L̇ect. Ser., III. ed., p. 723, C. C. Thomas, Springfield. - 57. Brown, I. A. (1964), Biochem. Clinics 3, 219-224. - 58. Müring, D. (1266), Verh. Deut. Ges. Inn. Med. 75, 44-51. - 59. LOWENSTEIN, J. \& TORNHEIM (1971), Science 171, 397-400. - 60. Lesch, P. \& Schmidt, F. W. (1972), Eur. J. Clin. Invest. 2, 294. - 61. Hrcks, J. M., Young, D. S. \& Wooton, I. D. P. (1964), Clin. Chim. Acta 9, 228-235.

Priv. Doz. Dr. P. Lesch 3000 Hannover-Kleefeld Karl-Wiechert-Allee 9 (Germany) 